\section{Commentary: Make surgery great again}

\author{
Scott I. Reznik, MD
}

In this issue of the Journal, Rahouma and colleagues ${ }^{1}$ report the outcomes for clinical T3N1 non-small cell lung cancer (NSCLC) and remind the reader of the importance of surgery in these patients. As advances in systemic therapy, particularly immunotherapy and targeted therapy, are changing the treatment paradigm for advanced NSCLC, we need to remember the benefit of resection in selected patients with locally advanced disease. T3N1 disease is relatively rare and has been underrepresented or excluded from many randomized trials of IIIa lung cancer. ${ }^{2-5}$ This report is one of the few to focus on this specific subset. There is a trend toward decreased use of surgery in this population. ${ }^{5}$ The authors used the National Cancer Database, which captures approximately $70 \%$ of new cancer diagnoses and may provide a reflection of current practice patterns. The authors harness the strength of this database while acknowledging its limitations. The National Cancer Database does not include clinical information such as pulmonary function, performance status, and tumor location, which are vital components of clinical decision-making. It could be postulated that some of the survival benefit seen in surgical patients may be derived from a healthier cohort of surgical candidates and not from the superiority of surgical therapy; conversely, a less healthy, nonoperative patient population may be associated with poorer outcomes. The 2 patient populations were not equivalent with differences in age, comorbidity, race, and histology. However, the robust propensity matching accounts for these differences.

This study spans 2 different staging systems and differs from the current staging system. The definition of T3 has evolved. Early in the study period, tumor size was not a criterion for T3, whereas later it included tumors larger

From the Division of General Thoracic Surgery, Department of Cardiovascular and Thoracic Surgery, University of Texas Southwestern Medical Center, Dallas, Tex. Disclosures: Author has nothing to disclose with regard to commercial support.

Received for publication Feb 16, 2020; accepted for publication Feb 16, 2020; available ahead of print Feb 21, 2020.

Address for reprints: Scott I. Reznik, MD, Department of Cardiovascular and Thoracic Surgery, University of Texas Southwestern Medical Center, 5323 Harry Hines Blvd, MC 8879, Dallas, TX 75390-8879 (E-mail: scott.reznik@ utsouthwestern.edu).

J Thorac Cardiovasc Surg 2021;161:264-5

$0022-5223 / \$ 36.00$

Copyright (c) 2020 by The American Association for Thoracic Surgery

https://doi.org/10.1016/j.jtcvs.2020.02.065

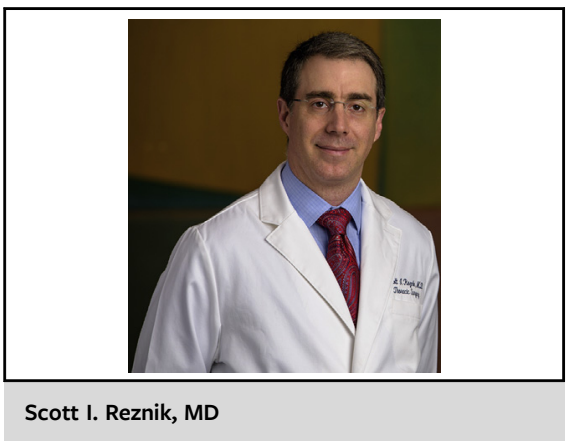

CENTRAL MESSAGE

Surgery with adjuvant therapy remains the optimal therapy for T3N1 non-small cell carcinoma of the lung in appropriate patients.

than $7 \mathrm{~cm}$; currently T3 tumors include tumors between 5 and $7 \mathrm{~cm}$. Interestingly, only $3.5 \%$ of patients underwent chest wall resection. Clinicians could consider using the data presented to help make treatment decisions for tumors previously classified as $\mathrm{T} 3$ but are now considered $\mathrm{T} 4$ by size. The clinical staging was found to be inaccurate in almost $30 \%$ of surgical patients, with $19.4 \%$ being overstaged and $9.6 \%$ being understaged, reinforcing the need for invasive mediastinal staging.

The near doubling of mortality from 30 days to 90 days needs to be considered when counseling patients; the authors reported $3.3 \%$ to $6.2 \%$ at 30 and 90 days, respectively, for lobectomy/bilobectomy, and $7.1 \%$ and $14.1 \%$ for primary pneumonectomy. Similarly, in patients receiving neoadjuvant therapy, the mortality was $3.1 \%$ and $5.1 \%$ (lobectomy) and $4.7 \%$ and $14.0 \%$ (pneumonectomy) at 30 and 90 days. ${ }^{1}$ Despite the sobering mortality data, the survival curves between the surgical and chemoradiation groups appear to diverge as early as 2 years. This study does not address the need for neoadjuvant therapy for T3N1 disease; more than $20 \%$ of the surgical patients received neoadjuvant therapy. Surgical mortality appeared similar in both groups. This decision may be best left to multidisciplinary teams. Rahouma and colleagues have provided ample reasons to keep surgery at the forefront of therapy for this disease.

\section{References}

1. Rahouma M, Kamel M, Nasar A, Harrison S, Lee B, Port J, et al. Treatment of cT3N1M0/IIIA non-small cell lung cancer and the risk of underutilization of surgery. J Thorac Cardiovasc Surg. 2021;161:256-63.e1.

2. Albain KS, Swann RS, Rusch VW, Turrisi AT, Shepherd FA, Smith C, et al. Radiotherapy plus chemotherapy with or without surgical resection for stage III non-small-cell lung cancer: a phase III randomised controlled trial. Lancet. 2009;374:379-86. 
3. Arriagada R, Bergman B, Dunant A, Le Chevalier T, Pignon JP, Vansteenkiste J. International Adjuvant Lung Cancer Trial Collaborative Group. Cisplatin-based adjuvant chemotherapy in patients with completely resected non-small-cell lung cancer. $N$ Engl J Med. 2004;350:351-60.

4. Kawaguchi K, Miyaoka E, Asamura H, Nomori H, Okumura M, Fujii Y, et al. Modern surgical results of lung cancer involving neighboring structures: a retrospective analysis of 531 pT3 cases in a Japanese Lung Cancer Registry Study. J Thorac Cardiovasc Surg. 2012;144:431-7.

5. Speicher PJ, Englum BR, Ganapathi AM, Onaitis MW, D'Amico TA Berry MF. Outcomes after treatment of 17,378 patients with locally advanced (T3N0-2) non-small-cell lung cancer. Eur J Cardiothorac Surg. 2015;47: 636-41.
See Article page 256.

\section{Commentary: Is surgery better than chemoradiation for T3N1M0 non-small cell lung cancer?}

\author{
Chi-Fu Jeffrey Yang, MD
}

Currently, there are few guidelines on how to treat clinical T3N1M0 stage IIIA non-small-cell lung cancer (NSCLC). The recommendations on locally advanced lung cancer from the American College of Chest Physicians ${ }^{1}$ and the European Society for Medical Oncology ${ }^{2}$ do not specifically detail algorithms for T3N1M0 NSCLC. The National Comprehensive Cancer Network (NCCN) does provide treatment recommendations for T3N1M0 NSCLC, ${ }^{3}$ but perhaps because T3N1M0 NSCLC is relatively uncommon (especially compared with T3N0 NSCLC or T3N2 NSCLC), ${ }^{4}$ data supporting the NCCN treatment guidelines for T3N1M0 NSCLC are limited. Until now, there have been no randomized trials or prospective or retrospective studies specifically comparing definitive chemoradiation and surgery for T3N1M0 NSCLC.

In this issue of the Journal, Rahouma and colleagues ${ }^{5}$ provide much-needed data on outcomes of surgery versus definitive chemoradiation for patients with T3N1M0 NSCLC. The authors evaluated 1937 patients who underwent surgery (with induction and/or adjuvant chemotherapy with or without radiation) and 1844 patients who underwent definitive chemoradiation for clinical T3N1M0 NSCLC

\footnotetext{
From the Department of Cardiothoracic Surgery, Stanford University Medical Center, Stanford, Calif.

Disclosure: Author has nothing to disclose with regard to commercial support

Received for publication March 16, 2020; revisions received March 16, 2020; accepted for publication March 16, 2020; available ahead of print April 6, 2020.

Address for reprints: Chi-Fu Jeffrey Yang, MD, Department of Cardiothoracic Surgery, Stanford University Medical Center, 300 Pasteur Drive, Falk Building 2nd

Floor, Stanford, CA 94305-5407 (E-mail: cjyang@post.harvard.edu).

J Thorac Cardiovasc Surg 2021;161:265-6

$0022-5223 / \$ 36.00$

Copyright (c) 2020 by The American Association for Thoracic Surgery

https://doi.org/10.1016/j.jtcvs.2020.03.106
}

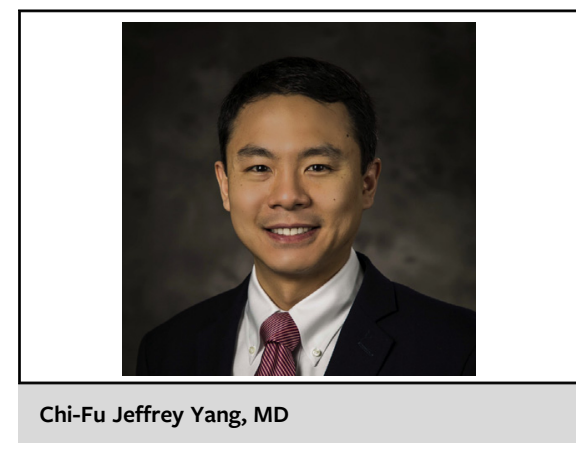

CENTRAL MESSAGE

In appropriately selected patients, surgery for T3N1Mo lung cancer is likely associated with improved survival compared with definitive chemoradiation, but further research evaluating different types of T3 tumors is needed.

between 2004 and 2014. They found that in the surgery group, among patients who did not receive preoperative chemotherapy or radiation $(\mathrm{n}=1518), 19 \%$ had pathological N0 disease and 9.5\% had pN2 disease. The surgery group had better survival than the definitive chemoradiation group in unadjusted and multivariable analyses. The authors also performed a propensity score-matched analysis in which they created a cohort of 1081 patients with cT3N1M0 NSCLC who underwent surgery (with induction and/or adjuvant chemotherapy with or without radiation) with similar baseline characteristics as 1081 patients who underwent definitive chemoradiation. Five-year overall survival was significantly greater for the surgery group when compared with the definitive chemoradiation group $(35.7 \%$ vs $19.0 \%)$.

The study has several strengths. By using the National Cancer Data Base, the authors were able to include a large 